\title{
Interobserver analysis of safety practices and behaviors adopted by elderly people to prevent falls
}

\author{
Cristina Rosa Soares Lavareda Baixinho ${ }^{1}$ \\ (iD) https://orcid.org/0000-0001-7417-1732 \\ Maria dos Anjos Coelho Rodrigues Dixe ${ }^{2}$ \\ (1D) https://orcid.org/0000-0001-9035-8548 \\ Carla Madeira $^{3}$ \\ (D) https://orcid.org/0000-0002-8911-3495 \\ Silvia Alves ${ }^{4}$ \\ (1D) https://orcid.org/0000-0002-8525-2068 \\ Maria Adriana Henriques 5 \\ (D) https://orcid.org/0000-0003-0288-6653
}

Escola Superior de Enfermagem de Lisboa, Fundamentos de Enfermagem, Lisboa, Lx, Portugal.

2 Instituto Politécnico de Leiria, Escola Superior de Saúde, Leiria, Lr, Portugal.

3 Hospital de VIla Franca de Xira, Medicina, Vila Franca de Xira, VFX, Portugal.

${ }^{4}$ Hospital de VIla Franca de Xira, Unidade de Cuidados Intensivos, Vila Franca de Xira, VFX, Portugal.

${ }^{5}$ Escola Superior de Enfermagem de Lisboa, Enfermagem Comunitária, Lisboa, LX, Portugal.
Objective: determine the psychometric properties of the safety practices and behaviors dimension of the Scale of Practices and Behaviors of Institutionalized Elderly People to Prevent Falls in a sample of elderly people with cognitive decline. Method: methodological study, with a quantitative approach, to assess the psychometric properties of the mentioned scale in a sample with 102 elderly people with cognitive decline who lived in two long-term care institutions for the public in this age group. Internal consistency evaluation was carried out by calculating the Cronbach's alpha coefficient; interobserver reliability was expressed by Cohen's kappa coefficient; and temporal stability, by obtaining Spearman correlation. Compliance with all ethical procedures was observed. Results: the dimension of safety practices and behaviors showed $a=0.895$ for its 11 items. Seven out of the 11 items reached good to excellent agreement among the experts for interobserver reliability. Kappa index values indicated that the instrument is valid and reliable. Safety practices and behaviors were influenced by institutionalization time, being at least 85 years old, and gait skills. Conclusion: the results pointed out that the instrument has good reproducibility and is valid and reliable, which allows its use in clinical practice in elderly people with cognitive decline as well as in research.

Descriptors: Geriatric Nursing; Validation Studies; Psychometrics; Accidental Falls; Elderly; Home for the Aged.

\section{How to cite this article}

Baixinho CRSL, Dixe MACR, Madeira C, Silvia A, Henriques MA. Interobserver analysis of safety practices and behaviors adopted by elderly people to prevent falls. Rev. Latino-Am. Enfermagem. 2020;28:e3268.

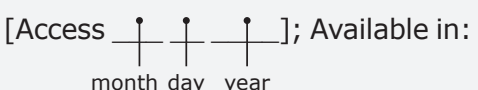
DOI: http://dx.doi.org/10.1590/1518-8345.3209.3268. 


\section{Introduction}

Falls, being the main accident in the elderly population, are considered a serious public health issue. Because of their consequences in functioning and the dependence and loss in quality of life they cause ${ }^{(1)}$, they are one of the main causes of death, disability, and costs to the health system, accounting for $85 \%$ of traumas in elderly people(2).

This problem is difficult to control because of the multifactorial nature of its genesis, which imposes the need for prevention. Despite this difficulty, researchers have emphasized that most risk factors are modifiable by introducing single or multiple interventions oriented toward one or more risk factors ${ }^{(1-6)}$.

One example is the environmental changes in elderly people's houses. It is known that nearly every house has fall risk factors for elderly people because of deficient lighting and the presence of rugs and obstacles that reduce indoor accessibility and mobility, among other problems ${ }^{(3)}$. Environmental risks can be minimized or eliminated by implementing behavioral changes in the elderly population in combination with modifications in the environment, resulting in a positive impact on the reduction of risks and on the prevalence of falls in elderly people's houses(4-5).

When mentioning the difficulties faced to carry out preventive actions, some authors have criticized the role played by research. They have noticed that the biomedical model has controlled evidence production in the fall research field, imposing the positivist $r$ esearch paradigm ${ }^{(6-7)}$.

This approach has offered gains, but researchers have stressed that it does not cover the complexity of fall events, their communication and the knowledge regarding elderly people's practices and behaviors concerning their communication, safe self-care practices, and other behavioral factors that may increase the chances of falls to occur ${ }^{(6-7)}$.

Consequently, it is necessary to explore other dimensions of the phenomenon and new interventions ${ }^{(6)}$. This is a question that pertains not only elderly people who live in the community, but mostly those who are institutionalized, given that they are more vulnerable, less independent, and more frequently affected by chronic diseases ${ }^{(1,6)}$. Most institutionalized elderly people have two or more comorbidities, with high blood pressure $(55.8 \%)$, dementia syndrome $(18.3 \%)$, diabetes mellitus (16.3\%), and Alzheimer's disease (14.4\%) being the most common diagnoses ${ }^{(1)}$. Polymedication adds to the list of risk factors, with $52 \%$ of the residents of long-term care institutions (LTCIs) taking eight or more different medications a day ${ }^{(1)}$.

Institutionalized elderly people also have to deal with the change in environment and the presence of employees and other elderly people, which are risk factors specific to LTCIs $^{(1)}$.

Additionally, more dependent, institutionalized elderly people have worse prevention practices and behaviors ${ }^{(6)}$, especially regarding self-care. Elderly people showing functional disability in one to five activities of daily living had a probability to fall $46 \%$ higher, and those showing functional disability in all activities of daily living had lower chances to fall (prevalence ratio $=0.57 ; 95 \%$ confidence interval: $0.34-0.96)^{(8)}$. Fall risk increases progressively with the increase in the level of dependence, except in totally dependent elderly people(9).

It is important to emphasize that cognitive alterations and deficits lead to functional decline, with a reduction and/or loss of skills, significantly interfering with practices and behaviors, which increases fall risk directly or indirectly.

Finding out the practices and behaviors of people with cognitive decline contributes to a more comprehensive discussion on fall risk dimensions other than biophysiological ones and may bring new elements to the debate about fall prevention measures in this public. The authors of the present study did not find instruments validated to examine practices and behaviors of institutionalized elderly people with cognitive decline to prevent falls in the literature.

The main objective of the present study was to determine the psychometric properties of the safety practices and behaviors dimension of the Scale of Practices and Behaviors of Institutionalized Elderly People to Prevent Falls (SPBIEPPF) in a sample of elderly people with cognitive decline.

\section{Method}

Methodological study, with a quantitative approach, to assess the psychometric properties of the SPBIEPPF safety practices and behaviors dimension in a sample of elderly people with cognitive decline.

The SPBIEPPF has two dimensions: the first concerns to practices and behaviors of bilateral communication between elderly people and different professionals at LTCIs, and the second is related to safety practices and behaviors adopted by elderly people. The latter dimension is made up of two factors, one pertaining safety practices and behaviors in self-care (first seven items) and another addressing practices and behaviors related 
to the accessibility in the physical space (last four items). Each item scores from 1 (never) to 5 (always). This scale was designed by Portuguese researchers and validated in a sample with elderly people without cognitive decline who lived in six Portuguese LTCIs $^{(10)}$.

In the validation study of the scale, in which the elderly people themselves filled out the instrument ${ }^{(10)}$, both dimensions showed good internal consistency: the six items in the communication subscale obtained $a=0.881$, and in the adopted safety practices and behaviors dimension the 11 items provided $a=0.817^{(10)}$.

The SPBIEPPF communication practices and behaviors dimension scores between 6 and 30 points, and the safety practices and behaviors adopted by elderly people dimension from 11 to 55 points ${ }^{(10)}$.

The psychometric properties of the scale showed that it was reliable and measured the examined variables properly(10) for the sample of conscious and instructed elderly people with which it was validated. These properties were determined for each scale dimension ${ }^{(10)}$ to allow its use in modules, according to the evaluation needs.

The importance of assessing safety practices and behaviors in populations with cognitive decline justifies the validation of this dimension by observation.

For the present study, the number of answer options was changed from five to three (never, sometimes, and always) to make its application easier with the observation method, a need imposed by the presence of cognitive decline in the target population.

The population of the present study was 204 elderly people who lived in two LTCIs, which authorized its execution. The final sample was 102 elderly people who met the predefined inclusion criteria: being at least 65 years old, being institutionalized, and showing cognitive decline as assessed by applying the Mini-Mental State Examination (MMSE, version in Portuguese) ${ }^{(11)}$ : $\leq 15$ points for illiterate people, $\leq 22$ for people with up to 11 years of formal education, and $\leq 27$ for people with more than 11 years of formal education)(11).

Elderly people who were totally dependent to carry out activities of daily living and those who experienced falls during the study period because of the influence of the fear of falling on the residents' practices and behaviors were excluded. The level of dependence was evaluated by obtaining the Barthel index by applying the instrument validated for the Portuguese population ${ }^{(12)}$. The elderly people who could walk around were evaluated regarding the use or not of an auxiliary gait device.

Data collection occurred between March and November 2017 and was carried out by four nurses specialized in rehabilitation nursing, two at each institution. First, a training addressing the scale structure, its variables, and the observation application mode was offered to the nurses. Subsequently, a pretest was performed, with the application of the scale to seven elderly people with cognitive decline who were not included in the final sample to train the professionals and make it possible to identify difficulties in the observation process and the completion of the instrument.

Last, the scale was applied by the professionals, who were independent observers, with a one-week interval between the evaluation of each one of them. Consequently, for interobserver reliability analysis, each elderly person was watched by two professionals while carrying out activities of daily living, over one week, in different moments. Fall occurrence was monitored and registered in the clinical process.

The scale internal consistency was assessed by obtaining the Cronbach's alpha coefficient, which is indicated for Likert-like scales with a number of answers higher than two, and which evaluates whether the total variance of the test results is associated with the sum of the variance for each item ${ }^{(13)}$.

Interobserver reliability was determined by calculating the kappa coefficient ${ }^{(14)}$, and temporal stability was expressed by Pearson's correlation coefficient. The interpretation of the magnitude of the kappa agreement estimators is, by convention: $\geq 0,75$ (excellent); 0,40 a

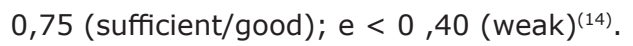

Data statistical treatment was performed by using the SPSS version 23.0 software.

The present study was developed in the scope of the project Gestão do Risco de Queda em Equipamentos para Idosos, approved by the Ethics Commission at the Universidade Católica Portuguesa. The ethical principles in the Declaration of Helsinki were met in the execution of the present study, namely informed consent, privacy, and confidentiality ${ }^{(15)}$.

\section{Results}

The sample was 102 elderly people with cognitive decline (MMSE $\leq 15$ points for illiterate people, $\leq 22$ for people with up to 11 years of formal education, and $\leq 27$ for people with more than 11 years of formal education) ${ }^{(11)}$ of both genders, with $73.5 \%$ of women and $26.5 \%$ of men, institutionalized for $43.29 \pm 41.64$ months, and $69.6 \%$ at least 85 years old (Table 1 ).

Although the present study did not have the objective of identifying fall prevalence, monitoring this indicator allowed to detect that it was high in both LTCIs. It was found that $40.2 \%$ of the elderly people

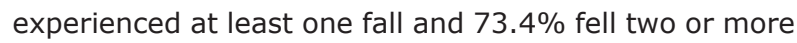
times over the past year. 
Table 1 - Characterization of elderly people who lived in two LTCIs regarding age, gender, fall occurrence, level of dependence, and use of auxiliary gait devices. Lisbon, Lx, Portugal, 2018

\begin{tabular}{|c|c|}
\hline \multicolumn{2}{|c|}{ Sample characterization } \\
\hline $\begin{array}{l}\text { Age (years) } \\
\qquad \begin{array}{l}\geq 6 \text { and }<75 \\
\geq 75 \text { and }<85 \\
\geq 85\end{array}\end{array}$ & $\begin{array}{c}\text { Percentage } \\
2.9 \% \\
27.5 \% \\
69.6 \%\end{array}$ \\
\hline $\begin{array}{l}\text { Gender } \\
\quad \text { Female } \\
\text { Male }\end{array}$ & $\begin{array}{l}73.5 \% \\
26.5 \%\end{array}$ \\
\hline $\begin{array}{l}\text { Fall episodes over the previous year } \\
\text { Yes } \\
\text { No }\end{array}$ & $\begin{array}{l}40.2 \% \\
59.8 \%\end{array}$ \\
\hline $\begin{array}{l}\text { Recurrent fall } \\
\text { Yes } \\
\text { No }\end{array}$ & $\begin{array}{l}73.4 \% \\
26.6 \%\end{array}$ \\
\hline $\begin{array}{l}\text { Injury resulting from the fall } \\
\text { Yes } \\
\text { No }\end{array}$ & $\begin{array}{l}51.3 \% \\
48.7 \%\end{array}$ \\
\hline $\begin{array}{l}\text { Level of dependence } \\
\text { None (independent) } \\
\text { Low } \\
\text { Intermediate } \\
\text { High }\end{array}$ & $\begin{array}{c}18.8 \% \\
26.6 \% \\
49.2 \% \\
5.4 \%\end{array}$ \\
\hline $\begin{array}{l}\text { Gait } \\
\text { Does not use an auxiliary gait device } \\
\text { Uses an auxiliary gait device } \\
\text { Stick } \\
\text { Crutches } \\
\text { Walker } \\
\text { Wheelchair (independently) } \\
\text { Wheelchair (needs help) }\end{array}$ & $\begin{array}{c}8.9 \% \\
90.1 \% \\
4.0 \% \\
10.9 \% \\
10.9 \% \\
1.0 \% \\
61.4 \%\end{array}$ \\
\hline
\end{tabular}

Table 2 shows kappa agreement coefficient ( $\kappa$ ) values for each one of the items of the SPBIEPPF safety practices and behaviors dimension. It was not possible to determine the coefficient for items 7 and 8 because they showed constant values, that is, both observers chose the same answer option. For the other items, the values varied from 0.369 to 0.922 . The indicators "opts to wear shoes with non-slip soles", "organizes their bedroom's space to facilitate moving in it", "removes obstacles that hinder gait in the bedroom", "ensures that their feet are well supported on the ground before standing", and "verifies if the bathroom floor is not slippery/wet before using the room" showed an excellent level of agreement, statistically significant for $p<0.001$.

The SPBIEPPF safety practices and behaviors dimension showed very good internal consistency, with a total Cronbach's alpha equal to 0.895 for its 11 items, and had the evaluation performed by both Observer 1 $(a=0.843)$ and Observer $2(a=0.854)$.

Considering the obtained kappa values and the fact that there was a one-week interval between the two evaluations, the authors opted to calculate temporal stability by obtaining Pearson's correlation coefficient. The calculated value $(r=0.936 ; p<0.001)$ indicated that there was a very strong, positive, and very significant correlation between the two evaluations.
Regarding the evaluation of practices and behaviors of elderly people with cognitive decline, according to the data collected by observation and taking into account that the values associated with each one of the items ranged from 1 to 3 , it was found that the examined institutionalized elderly people with cognitive decline had good fall prevention practices (Table 3).

Table 2 - Determination of interobserver agreement as expressed by the kappa agreement coefficient. Lisbon, Lx, Portugal, 2018

\begin{tabular}{|c|c|c|c|}
\hline \multicolumn{4}{|c|}{ Safety practices and behaviors dimension } \\
\hline Indicator & $\mathbf{K}^{*}$ & $\mathbf{p}^{\dagger}$ & agreement \\
\hline $\begin{array}{l}\text { 1. Seeks to persevere in } \\
\text { choosing the best fall prevention } \\
\text { measures }\end{array}$ & .789 & $<0.001$ & Excellent \\
\hline $\begin{array}{l}\text { 2. Selects shoes that are suitable } \\
\text { for their feet }\end{array}$ & .369 & $<0.001$ & Weak \\
\hline 3. Opts to wear closed-toe shoes & .712 & $<0.001$ & Good \\
\hline $\begin{array}{l}\text { 4. Opts to wear shoes with non- } \\
\text { slip soles }\end{array}$ & .922 & $<0.001$ & Excellent \\
\hline $\begin{array}{l}\text { 5. Organizes their bedroom's } \\
\text { space to facilitate moving in it }\end{array}$ & .882 & $<0.001$ & Excellent \\
\hline $\begin{array}{l}\text { 6. Removes obstacles that } \\
\text { hinder gait in the bedroom }\end{array}$ & .826 & $<0.001$ & Excellent \\
\hline 7. Keeps the bed wheels stopped & $.000^{\ddagger}$ & & \\
\hline $\begin{array}{l}\text { 8. When getting up off the bed, } \\
\text { first seats, with their feet well } \\
\text { supported on the ground, and } \\
\text { only then stands up }\end{array}$ & $.000^{\ddagger}$ & & \\
\hline $\begin{array}{l}\text { 9. Ensures that their feet are well } \\
\text { supported on the ground before } \\
\text { standing }\end{array}$ & .841 & $<0.001$ & Excellent \\
\hline $\begin{array}{l}\text { 10. Verifies if the bathroom floor } \\
\text { is not slippery/wet } \\
\text { before using the room }\end{array}$ & .853 & $<0.001$ & Excellent \\
\hline $\begin{array}{l}\text { 11. Ensures that the floor is } \\
\text { not slippery before carrying out } \\
\text { hygiene care }\end{array}$ & .370 & $<0.001$ & Weak \\
\hline
\end{tabular}

Table 3 - Sample characterization regarding practices and behaviors to prevent falls. Lisbon, Lx, Portugal, 2018

\begin{tabular}{|c|c|c|c|}
\hline Indicator & Mean & Median & SD* $^{*}$ \\
\hline Practices and behaviors total result & 31.45 & 33.00 & 2.34 \\
\hline $\begin{array}{l}\text { 1. Seeks to persevere in choosing the } \\
\text { best fall prevention measures }\end{array}$ & 2.83 & 3.00 & .375 \\
\hline $\begin{array}{l}\text { 2. Selects shoes that are suitable for } \\
\text { their feet }\end{array}$ & 2.90 & 3.00 & .299 \\
\hline 3. Opts to wear closed-toe shoes & 2.95 & 3.00 & .217 \\
\hline $\begin{array}{l}\text { 4. Opts to wear shoes with non-slip } \\
\text { soles }\end{array}$ & 2.59 & 3.00 & .569 \\
\hline $\begin{array}{l}\text { 5. Organizes their bedroom's space to } \\
\text { facilitate moving in it }\end{array}$ & 2.59 & 3.00 & .569 \\
\hline $\begin{array}{l}\text { 6. Removes obstacles that hinder gait in } \\
\text { the bedroom }\end{array}$ & 2.91 & 3.00 & .285 \\
\hline 7. Keeps the bed wheels stopped & 3.00 & 3.00 & .000 \\
\hline $\begin{array}{l}\text { 8. When getting up off the bed, first } \\
\text { seats, with their feet well supported on } \\
\text { the ground, and only then stands up }\end{array}$ & 3.00 & 3.00 & .000 \\
\hline
\end{tabular}


Table 3 - (continuation)

\begin{tabular}{|c|c|c|c|}
\hline Indicator & Mean & Median & SD* $^{*}$ \\
\hline $\begin{array}{l}\text { 9. Ensures that their feet are well } \\
\text { supported on the ground before } \\
\text { standing }\end{array}$ & 2.89 & 3.00 & .312 \\
\hline $\begin{array}{l}\text { 10. Verifies if the bathroom floor is not } \\
\text { slippery/wet } \\
\text { before using the room }\end{array}$ & 2.83 & 3.00 & .375 \\
\hline $\begin{array}{l}\text { 11. Ensures that the floor is not slippery } \\
\text { before carrying out hygiene care }\end{array}$ & 2.95 & 3.00 & .217 \\
\hline
\end{tabular}

The totality of the safety practices and behaviors dimension ( $t=.842 ; p>0.05)$ as well as the 11 items that make it up are not correlated with gender, but the totality of the dimension showed a correlation with institutionalization time (.355; $\mathrm{p}<0.001)$. Analysis of the relationship between each one of the indicators and institutionalization time showed that the differences occurred in items 4 ( $r s=0.220 ; p<0.01), 5$ ( $r s=0.205$; $\mathrm{p}<0.01)$, and 10 ( $r s=0.164 ; \mathrm{p}<0.05)$.

The residents who did not have gait alterations showed better practices (32.5 \pm 31.2$)$ when compared to those who had this type of alterations $(29.00 \pm 2.3)$, with the difference having a statistical meaning $(t=10.053 ; p<0.001)$.

The elderly people who were 85 years old or older had better practices $(31.7 \pm 2.0)$ than those who were less than 85 years old $(30.7 \pm 2.9)$, with the difference showing a statistical meaning $(t=-2.143 ; p<0.05)$.

The possibility that fall prevalence was related to age was tested. However, the differences obtained did not have a statistical meaning $\left(x^{2}=.056 ; p>0.05\right)$.

The association of fall occurrence in elderly people with cognitive decline over the previous year with their practices allowed to verify that the practices of the residents who fell during that period $(31.7 \pm 2.3)$ did not show a differences with a statistical meaning $(t=1.811$; $p>0.05)$ when compared with those of the residents who did not fall $(31.07 \pm 2.3)$.

\section{Discussion}

Falls, fall risk, and the fear of falling are focuses of attention for nurses' clinical practice and are related to transitions in the health-disease process of elderly people and to the institutionalization process. This phenomenon is one of the reasons mentioned by relatives to seek an institution. Its repetition and consequences may lead to institutionalization, and it affects the residents who are still independent, given that they are living in a house designed for elderly people(16).

The increase in the average life expectancy will be followed by a higher number of falls with injuries, which will interfere with institutionalized elderly people's quality of life. For this reason, some authors consider that fall prevalence must be an item of quality evaluation in LTCIs ${ }^{(17)}$.

Additionally, there is the fact that, after the first fall episode, elderly people impose restrictions to their activities or find themselves restrained by other people ${ }^{(1,18)}$ for fear of a new occurrence, which promotes dependence.

Taking into account this context and the absence of an instrument that assessed practices and behaviors of institutionalized elderly people with cognitive decline to help prevent falls, the authors of the present study tested the SPBIEPPF psychometric properties in a sample with 102 elderly people with cognitive decline resorting to four observers.

Reliability analysis showed that the 11 items of the SPBIEPPF safety practices and behaviors dimension showed a very good reliability level and had internal consistency. These results expressed the scale potential to measure practices and behaviors of elderly people with cognitive decline to prevent fall episodes.

It is important to emphasize that the initial version of the instrument has a dimension addressing communication practices, which is a core element in any fall prevention program. Some authors advocate that improving the communication about preventive measures and health promotion between residents and professionals may ensure that appropriate and specific interventions are carried out to reduce fall incidence ${ }^{(6,19)}$, which is especially high in people with cognitive alterations and increases costs with health resources ${ }^{(9)}$. However, communication alterations induced by cognitive decline, encompassing confusion periods, changes in verbal and nonverbal language, and processing alterations, among others, do not allow to assess this dimension in the population with cognitive deficit.

A study that applied the SPBIEPPF to institutionalized elderly people who did not have cognitive decline concluded that there is a depreciation in the communication about falls in LTCIs, which may reinforce a depreciation of the frequency with which risk factors contribute to fall episodes and the assumption that this phenomenon is natural in this age group(6).

The authors of this study mentioned that the worst possible total value/obtained value ratio occurred for the practices and behaviors of communication about risk factors between elderly people and institution professionals dimension. An average equal to 7.52 \pm 3.24 out of a possible total value equal to $30^{(6)}$ was obtained. Future studies must characterize how communication about risk factors, about preventive measures, and about fall episodes affecting people with cognitive decline is carried out, which involves essentially the different professionals and the elderly people who do not have cognitive decline who witness falls of residents with cognitive impairment. 
The safety practices and behaviors of elderly people dimension is made up of two parts, the first addressing safe practices and behaviors in self-care (items 1 to 7) and the second dealing with practices and behaviors related to the accessibility in the physical space (items 8 to 11 ). These parts equally showed a slight difference in the value of Cronbach's alpha, which was $a=0.895$, in comparison with the value calculated when the scale was validated, which was $a=0.814$.

This value indicated good internal consistency. Future studies must investigate whether the fact that elderly people with cognitive decline concomitantly show physical impairments, for instance gait alterations that imply the use of auxiliary gait devices, increases the incidence of safety practices in self-care and impel them to have more caution when planning the organization of the physical space to improve accessibility in it.

The results of the study already mentioned pointed out that the practices and behaviors that occur most often, on average, are those related to self-care, namely choosing shoes with non-slip soles (4.06 \pm 1.11$)$ and close-ended shoes $(3.45 \pm 1.35)$ and getting up off the bed in a specific way, in which "most times" elderly people ensure that their feet are well supported on the ground before standing up $(3.97 \pm 1.27)^{(6)}$.

Regarding the evaluation of the interobserver agreement index, the present study found that seven out of the 11 items obtained good to excellent agreement. Based on these results, it is possible to consider that these items showed a good agreement among the experts and a good reproducibility concerning the assessment of practices and behaviors by hetero-observation.

Items 2 and 11 showed a low interobserver reliability. The difficulty in obtaining consensus may be a consequence of the nature of the activity, that is, the observers may have different assumptions about the capacity that elderly people with cognitive decline have to select proper shoes or ensure that the floor is not slippery.

Because of the importance these variables have in the mechanism of fall episodes and their prevention, they must be explored in future studies.

Items 7 and 8 showed constant values, which did not allow the determination of the kappa value.

It is possible that the results may have been influenced by random mistakes or measurement bias. One of the factors that may have affected them is the prejudice professionals may have against cognitive decline and against the skills a person in this situation may have.

The researchers that will apply this instrument in future studies must address this aspect with the observers. These have to be trained about the construct, its descriptors, the ideal conformity index, evaluation criteria, the standardization of the evaluation process $^{(20)}$, and how differences and individual perceptions may bias objective evaluation.

Despite these difficulties, the findings pointed to the reliability of the indicators and of the instrument, indicating objectivity in the measurement. It is important to emphasize that reliability and agreement are not established properties of measurement instruments. Instead, they result from the interaction between the tool, the subjects or objects, and the context in which the evaluation is carried out(20-21).

Statistical analysis showed that the practices and behaviors of elderly people with cognitive decline were good, given that the sample scored 31.45 out of a total of 33 points. The indicators with higher averages were "keeps the bed wheels stopped" and "when getting up off the bed, first seats, with their feet well supported on the ground, and only then stands up". This practice may impact fall prevention, because $25.7 \%$ of falls in LTCIs occur when people are getting up off the bed and $37.1 \%$ during gait ${ }^{(1)}$.

The results of the present study emphasized the difference in elderly people's practices according to these people's gait skills. The residents who had no gait alterations showed better practices $(32.5 \pm 31.2)$ when compared with those who had alterations of this nature $(29.00 \pm 2.3)$. This factor may increase fall risks, because it adds to a major risk (gait alterations) unsafe practices related to self-care and accessibility in the physical space, both relevant risks in the genesis of the fall mechanism ${ }^{(1,3-5)}$.

There was no association between the occurrence of fall episodes over the previous year and the practices and behaviors of elderly people with cognitive decline. The instruments used to evaluate the fear of falling have not been validated for the population with cognitive decline, but this alteration contributes to determining the perception of fall occurrence and of the fear of falling.

The issue under discussion is complex and raises questions about the systematization and organization of nursing care. It is important that teams be trained ${ }^{(22)}$ and programs structured toward interventions that include training, leadership, mutual support, monitoring, and communication $^{(23)}$.

Educational programs intended for professionals are a positive cost-effectiveness method to improve strategies oriented toward fall prevention ${ }^{(24)}$. The intervention must predict not only the approach to control biophysiological and environmental risk factors, but also practices and behaviors, especially of elderly people with cognitive decline, so professionals keep a closer look at them and help more fragile elderly people keep safe.

The limitations of the present study were related to the sample and the latent variable that was examined. Evaluating the practices and behaviors of elderly people with cognitive decline is a complex process, which requires 
training, experience, and time and, because doing it systematically in LTCIs is not habitual, the observers may have been influenced by their self-perception of the behavior of the residents with cognitive decline.

The absence of studies on practices and behaviors in the management of fall risk and the characteristics of the examined population hindered data discussion.

\section{Conclusion}

The psychometric characteristics of the scale and the association of the items with preventive measures that help control the main fall risks indicated that the instrument under discussion is useful to evaluate the practices and behaviors of elderly people regarding fall prevention.

Internal consistency analysis showed that the scale had $a=0.895$ for its 11 items, which indicated its capacity to evaluate the latent variable.

Regarding the indicators' agreement and reliability, expressed by Cohen's kappa coefficient, the results pointed out that the instrument has good reproducibility, which showed that it is valid and reliable to measure the practices and behaviors of institutionalized elderly people with cognitive decline to prevent falls.

It was verified that the practices and behaviors of elderly people with cognitive decline regarding the management of fall risks were not associated either with gender or the occurrence of a previous fall episode, but instead are influenced by institutionalization time, being older than 85 years, and gait skills.

Determining the SPBIEPPF psychometric properties allows it to be used with statistical relevance in research and in the nursing practice when applied to elderly people with cognitive decline who live in LTCIs.

Future studies must associate communication, safety practices and behaviors in self-care, and practices and behaviors related to accessibility in the physical space with fall risk, fall prevalence, fall mechanism, and the fear of falling.

\section{Acknowledgments}

The authors thank the professionals and institutionalized elderly people who participated in the present study.

\section{References}

1. Baixinho $C L$, Dixe $M A$. Falls in institutions for older adults: characterization of fall occurrences and associated risk factors. Rev Eletr Enferm. [Internet]. 2015 Oct/Dec [cited Jun 23, 2018];17(4). Available from: http://dx.doi.org/10.5216/ree.v17i4.xxxx.
2. Matchar DB, Duncan PW, Lien CT, Ong MEH, Lee M., Gao F, et al. Randomized Controlled Trial of Screening, Risk Modification, and Physical Therapy to Prevent Falls Among the Elderly Recently Discharged From the Emergency Department to the Community: The Steps to Avoid Falls in the Elderly Study. Arch Phys Med Rehabil. 2017 Jun; 98(6):1086-96. doi: 10.1016/j. apmr.2017.01.014. Epub 2017 Feb 12.

3. Chacko TV, Prabha T, Gm M. How Fall-Safe Is the Housing for the Elderly in Rural Areas ? : A Cross Sectional Study Using Fall Prevention Screening Checklist. JIAG. [Internet]. 2017 Sep [cited Jun 23, 2018];13(3):124-30. Available from: http://www.jiag.org/jiagpdf/6_How\%20 Fall\%20Safe

4. Maggi $P$, de Almeida Mello J, Delve $S$, Cés $S$, Macq J, Gosset C, et al. Fall Determinants and Home Modifications by Occupational Therapists to Prevent Falls. Can J Occup Ther. 2018 Feb; 85(1):79-87. doi: $10.1177 / 0008417417714284$.

5. Luk JK, Chan TY, Chan DK. Falls Prevention in the Elderly: Translating Evidence into Practice. Hong Kong Med J. 2015 Apr; 21(2):165-71. doi: 10.12809/ hkmj144469. Epub 2015 Feb 27.

6. Baixinho $\mathrm{CL}$, Dixe $\mathrm{MA}$. What are the practices and behaviors of institutionalized seniors to prevent falls?. Index Enferm. [Internet]. 2017 [cited Jul 24, 2018]; 26(4):255-9. Available from: http://scielo. isciii.es/scielo.php?script=sci_arttext\&pid=S113212962017000300004\&lng=es

7. Hanson H, Salmoni AW, Doyle PC. Broadening our understanding: Approaching falls as a stigmatizing topic for older adults. Disabil Health J. 2009 Jan; 2(1):36-44. doi: 10.1016/j.dhjo.2008.11.001.

8. Del Duca GF, Antes DL, Hallal PC. Falls and fractures among older adults living in long-term care. Rev Bras Epidemiol. [Internet]. 2013 Mar [cited Jul 12, 2018];16(1):68-76. Available from: http://dx.doi. org/10.1590/S1415-790X2013000100007.

9. Davis JC, Dian L, Khan KM, Bryan S, Marra CA, Hsu $C L$, et al. Cognitive status is a determinant of health resource utilization among individuals with a history of falls: a 12-month prospective cohort study. Osteoporos Int. 2016 Mar; 27(3):943-51. doi: 10.1007/s00198015-3350-4. Epub 2015 Oct 8.

10. Baixinho CL, Dixe MA. Construction and Validation of the Scale of Practices and Behaviors of Institutionalized Elderly to Prevent Falls. UJPH. [Internet]. 2016 [cited Jul 14, 2018];4(3):139-43. Available from: http://dx.doi. org/10.13189/ujph.2016.040303

11. Guerreiro $M$, Silva AP, Botelho $M$, Leitão $O$, Castro-Caldas A, Garcia C. Adaptação à população portuguesa da tradução do Mini Mental State Examination. Rev Port Neurol. [Internet].1994[cited Jul 17, 2018]; 
1:9-10. Available from: https://www.scienceopen.com/ document?vid=97d4329c-9dba-49fe-9df1-db1215f3d4c5 12. Araújo F, Ribeiro JLP, Oliveira A, Pinto C. Validação do Índice de Barthel numa amostra de idosos não institucionalizados. Rev Port Saúde Pública. [Internet]. 2007 Apr [Acesso 12 jul 2018];25(2):59-66. Disponível em: http://www.cdi.ensp.unl.pt/docbweb/multimedia/ rpsp2007- 2/05.pdf

13. Maroco J, Garcia-Marques T. Qual a fiabilidade do Alfa de Cronbach? Questões antigas e soluções modernas? Lab Psicol. [Internet]. 2006 [Acesso 27 jun 2018];4(1):65-90. Disponível em: http://repositorio. ispa.pt/handle/10400.12/133

14. Miot HA. Agreement analysis in clinical and experimental trials. J Vasc Bras. [Internet]. 2016 Apr/ Jun [cited Jul 14, 2018];15(2):89-92. Available from: http://dx.doi.org/10.1590/1677-5449.004216

15. World Medical Association (WMA). Declaration of Helsinki - Ethical Principles for Medical Research Involving Human Subjects. JAMA. [Internet]. 2013 Oct [cited Jun 17, 2018];310(20):2191-4. Available from: https://www.wma.net/wp-content/uploads/2016/11/ DoH-Oct2013-JAMA.pdf

16. Álvarez Barbosa F, Del Pozo-Cruz B, Del Pozo-Cruz J, Alfonso-Rosa RM, Sañudo Corrales B, Rogers ME. Factors Associated with the Risk of Falls of Nursing Home Residents Aged 80 or Older. Rehabil Nurs. 2016 Jan-Feb; 41(1):16-25. doi: 10.1002/rnj.229. Epub 2015 Sep 24. 17. Sharifi F, Fakhrzadeh $H$, Memari A, Najafi B, Nazari N, Khoee MA, et al. Predicting risk of the fall among aged adult residents of a nursing home. Arch Gerontol Geriatr. [Internet]. 2015 Sep/Oct [cited Jun 14, 2018];61(2):124-30. Available from: http://dx.doi.org/: 10.1016/j.archger.2015.06.014. Epub 2015 Jun 22.

18. Marques-Vieira CMA, Sousa LMM, Severino S, Sousa L, Caldeira S. Cross-cultural validation of the falls efficacy scale international in Elderly: Systematic literature review. JCGG. [Internet]. 2016 Sep [cited Jun 2, 2018];7(3):72-6. Available from: http://dx.doi. org/10.1016/j.jcgg.2015.12.002

19. Duffy $A$. The assessment and management of falls in residential care settings. $\mathrm{Br}$ J Nurs. [Internet]. 2013 Mar [cited Jun 1, 2018];22(5):259-63. Available from: http://dx.doi.org/:10.12968/bjon.2013.22.5.259

20. Vituri DW, Évora YDM. Reliability of indicators of nursing care quality: testing interexaminer agreement and reliability. Rev. Latino-Am. Enfermagem. [Internet].

Corresponding author:

Cristina Lavareda Baixinho

E-mail: crbaixinho@esel.pt

(D) https://orcid.org/0000-0001-7417-1732
2014 Mar/Apr [cited jul 2, 2018];22(2):234-40. Available from: http://dx.doi.org/:10.1590/0104-1169.3262.2407 21. Kottner J, Audigé L, Brorson S, Donner A, Gajewsk $B$, Hróbjartsson $A$, et al. Guidelines for Reporting Reliability and Agreement Studies (GRRAS) were proposed. J Clin Epidemiol. 2011 Jan;64(1):96-106. doi: 10.1016/j.jclinepi.2010.03.002. Epub 2010 Jun 17. 22. Reis KMC, Jesus CAC. Cohort study of institutionalized elderly people: fall risk factors from the nursing diagnosis. Rev. Latino-Am. Enfermagem. [Internet]. 2015 Nov-Dec [cited Nov 20, 2019]; 23(6): 1130-8. Available from: http://dx.doi.org/10.1590/0104-1169.0285.2658

23. Cunha LFC, Baixinho CL, Henriques MA. Preventing falls in hospitalized elderly: design and validation of a team intervention. Rev Esc Enferm USP. [Internet]. 2019 Jul [cited Nov 20, 2019]; 53:e3479. Available from: http://dx.doi.org/10.1590/S1980-220X2018031803479 24. Alves VC, Freitas Weslen CJ, Ramos JS, Chagas SRG, Azevedo Ci, Mata LRF. Actions of the fall prevention protocol: mapping with the classification of nursing interventions. Rev. Latino-Am. Enfermagem. [Internet]. 2017 Dec [cited Nov 20, 2019]; 25: e2986. Available from: http://dx.doi.org/10.1590/1518-8345.2394.2986

Received: Nov 23rd 2018 Accepted: Feb $7^{\text {th }} 2020$

Associate Editor:

Rosalina Aparecida Partezani Rodrigues

Copyright @ $\mathbf{2 0 2 0}$ Revista Latino-Americana de Enfermagem This is an Open Access article distributed under the terms of the Creative Commons (CC BY).

This license lets others distribute, remix, tweak, and build upon your work, even commercially, as long as they credit you for the original creation. This is the most accommodating of licenses offered. Recommended for maximum dissemination and use of licensed materials. 